\title{
Sexualidade e religiosidade: A mulher no documentário Santo Forte (1999)
}

\author{
Gabriella Bertrami Vieira ${ }^{1}$
}

\section{Resumo}

Este artigo busca analisar o documentário Santo Forte (1999), de Eduardo Coutinho, pensando as relações entre instituições, manifestações e trânsitos religiosos, que se apresentam como mediadores entre o mundo profano e o sagrado. Para tanto, analisamos as narrativas de duas personagens mulheres e suas relações com o universo religioso brasileiro, em especial o afro-brasileiro. A obra trata de trajetórias religiosas de moradores da comunidade Vila Parque da Cidade (Zona Sul do Rio de Janeiro), e é composta por entrevistas feitas pelo diretor e sua equipe com dezoito moradores dessa localidade, entre os quais onze são mulheres. Nos relatos femininos, percebemos aspectos relevantes para pensar as relações entre o sagrado, a vida cotidiana e representações de mulheres periféricas, tanto no âmbito social, quanto afetivo, profissional e sexual.

Palavras-chave: documentário; religiões afro-brasileiras; mulheres.

\section{Sexuality and religiosity: the woman in the documentary Santo Forte (1999)}

\author{
Abstract
}

${ }_{1}^{1}$ Mestranda em História pelo Programa de Pós-Graduação em História da Universidade Estadual de Maringá (PPH/UEM). Bolsista CAPES. Orientanda da Prof. a Dra. Vanda Fortuna Serafim. E-mail: gabriella.bertrami@hotmail.com

GT 10 - Gênero e religiosidades 
This article intents to analyze the documentary Santo Forte (1999), by Eduardo Coutinho, considering the relations between institutions, manifestations, and religious transits, which present themselves as mediators between the profane and the sacred world. Therefore, we analyze the narratives of two female characters and their relationship with the Brazilian religious universe, especially the Afro-Brazilian one. The documentary is about religious trajectories of residents of the Vila Parque da Cidade community (South Zone of Rio de Janeiro) and consists of interviews made by the director and his team with eighteen residents of that location, among whom eleven are women. In female narratives, we perceive relevant aspects to think about the relationships between the sacred, ordinary life, and representations of peripheral women, in the social, emotional, professional, and sexual levels.

Keywords: documentary; afro-brasilian religions; women.

Este artigo tem como objetivo analisar o documentário brasileiro Santo Forte (1999), do diretor Eduardo Coutinho (1933-2014), com enfoque sobre as narrativas e representações das mulheres presentes na obra. Santo Forte é gravado na comunidade Vila Parque da Cidade entre outubro e dezembro de 1997, e lançada nos cinemas em 1999. A temática central são as trajetórias, comunicações e vivências com as diversas religiões que compõe o campo religioso brasileiro. Porém, a narrativa audiovisual abre espaço para diversas reflexões, como por exemplo, família, morte, amor, força, desigualdade, pluralismo e trânsitos religiosos, subjetividades, e, também sobre as representações das mulheres periféricas no cinema. Dos dezoito personagens, onze são mulheres, as quais narram as relações, conflituosas ou não com o sagrado, em sua vida, nos âmbitos sociais, de trabalho, afetividade e sexualidade. Utilizaremos duas personagens, Thereza e Carla, para analisar algumas representações e correspondências criadas no filme, sobre suas relações com o universo religioso brasileiro, em especial o afro-brasileiro.

Analisando as narrativas de personagens femininas procuramos pontuar a construção de um protagonismo dessas mulheres periféricas, 
que muitas vezes não tem direito à se auto narrar, e que em Santo Forte, encontram algum espaço de se reafirmar enquanto mulheres que fazem o que precisam e buscam na religião estratégias de sobrevivência, força e protagonismo. As discussões serão norteadas a partir de excertos da obra e colocadas em tensão com as contribuições de Mircea Eliade, Cláudia Mesquita, para pensar as relações entre personagem-narrativareligiosidade e, de Marcos Napolitano e Edgar Morin, para pensar o documentário enquanto fonte histórica.

Temos, através dos meios de comunicação, a crescente e intensa retratação dos fatos e, consequentemente, a tentativa de captar e transmitir uma realidade - mesmo sabendo que esse "retratar a realidade" nunca se dá de maneira absoluta, mas sim, como uma construção, como narrativas historicamente localizadas. Tal fato, chama a atenção dos historiadores, os quais passam, cada vez mais, a tratar desses fenômenos, principalmente pela utilização do audiovisual como fonte de pesquisa histórica. Isso se aplica a este trabalho, que tem como fonte de análise o documentário Santo Forte, intencionando a compreensão dos elementos que a compõe, atentando para seus código internos de funcionamento, específicos do cinema documentário; bem como de seu contexto sociocultural de produção, especialmente sob o enfoque das personagens femininas da obra e suas implicações com a religiosidade.

\section{A fonte audiovisual}

As discussões metodológicas acerca do cinema, e, mais especificamente do cinema documentário como fonte histórica são amplas e bastante variadas. O historiador Marcos Napolitano, introduz sua discussão sobre fontes audiovisuais e seu uso na História, com o enunciado de que, cada vez mais "tudo é dado a ver e a ouvir" (NAPOLITANO, 2005, p. 236), sejam fatos considerados importantes ou meramente triviais, indivíduos públicos e influentes ou anônimos, 
tratando de seu cotidiano. Ou seja, temos, através dos meios de comunicação, a crescente e intensa retratação dos fatos e, consequentemente, a tentativa de captar e transmitir uma realidade mesmo sabendo que esse "retratar a realidade" nunca se dá de maneira absoluta, mas sim, como uma construção, como narrativas historicamente localizadas. Tal fato, chama a atenção dos historiadores, os quais passam, cada vez mais, a tratar desses fenômenos, principalmente pela utilização do audiovisual como fonte de pesquisa histórica. Isso se aplica a este trabalho, que tem como fonte de análise o documentário Santo Forte, intencionando, a partir dela, a compreensão dos elementos que a compõe, de seu contexto sociocultural de produção, especialmente sob o enfoque das personagens femininas da obra e suas implicações com a religiosidade.

Diante de uma fonte audiovisual, um ponto em concordância entre as variadas propostas de abordagem para a mesma, é o de que sua análise é tarefa desafiadora, carregada de impasses, questionamentos, tensões e paradoxos. Este estatuto paradoxal que permeia fontes de natureza audiovisual, é marcado por uma tensão central, que Napolitano, destaca de maneira detalhada: tensão subjetividade/objetividade, ou evidência/representação. No caso do documentário, especificamente, temos de nos atentar à impressão de realidade que este carrega. Isso porque a própria ideia de obra documentária, nos remete, muitas vezes, a pensar a mesma como um documento dotado de um saber "verdadeiro" ou que apreende a "totalidade da realidade". Diante disso, neste trabalho, de acordo com as propostas do autor, consideramos utilizar uma abordagem que visa compreender a fonte em seu contexto e interpretá-la a partir do pressuposto de que ela é dotada de intencionalidades - do diretor, do tema proposto, dos discursos do período, da equipe de edição e montagem, dos financiadores, entre outros -, que é construída a partir de escolhas, de estruturas de linguagem e funcionamento, além de mecanismos e códigos internos próprios. 
Isso nos permite então direcionar a análise para a complexidade do cinema, sua íntima relação com o homem, com o imaginário e com o real; bem como a relação arte-indústria, não somente como antagônicas, mas também complementares e articuladas. Edgar Morin (2014), nesse sentido nos auxilia, pois não se pauta numa relação de exclusão entre o cinema ser ou indústria ou arte, mas sim, o que causa espanto, e, portanto, nos interessa, é que indústria e arte estão conjugadas numa relação mais ampla. Ou seja, o cinema está inserido no paradoxo

de que a produção (industrial, capitalista, estatal) tem necessidade ao mesmo tempo de excluir a criação (que é desvio, marginalidade, anomia, despadronização), mas também de incluí-la (porque ela é invenção, inovação, originalidade e toda obra precisa de um mínimo de singularidade), e tudo se faz de forma humana, aleatória, estatística e cultural no jogo criação/produção (MORIN, 2014, p. 16).

Ou seja, pensamos as produções cinematográficas como produto/produtor de uma realidade. Estas, não possuem um sentido universal, estável e imóvel. São investidos de significações diversas, construídas na negociação entre uma proposição e uma recepção, no encontro entre os pressupostos estabelecidos que lhes dão sua estrutura e os do público que delas se apropriam. Assim, quando temos uma narrativa cinematográfica como fonte de análise para a História, há a necessidade de nos atentarmos às propostas metodológicas que proporcionem maior esclarecimento aos fenômenos históricos circunscritos na produção/produtora, às maneiras de construção da narrativa cinematográfica e suas especificidades.

A partir disso nos encaminhamos para uma breve apresentação de Santo Forte. A fonte em questão é composta, fundamentalmente, por narrativas que tem como temática principal religiosidade, e é gravada em um único local, uma favela da Zona Sul do Rio de Janeiro: a Vila Parque da Cidade, na época com mais ou menos dois mil habitantes, para a qual Eduardo Coutinho e sua equipe se dirigem a fim de 
conversar com alguns moradores. A proposta e ideia de gravar um documentário sobre "trajetórias religiosas" em uma comunidade do Rio de Janeiro, surge, quando o diretor, Eduardo Coutinho, em 1996/1997 realizando um projeto inacabado sobre religiões no Brasil, para a então TV Educativa, entra em contato com o trabalho feito pelas antropólogas Patrícia Birman e Patrícia Guimarães, sobre o campo religioso brasileiro, a partir da comunidade Vila Parque da Cidade, pensando mais especificamente as relações dos indivíduos com a Igreja Universal do Reino de Deus, que resultou numa dissertação de mestrado, bem como num curta-metragem intitulado Pomba-gira (1998). ${ }^{2}$

A ideia de Coutinho era, então, de encontrar pessoas/personagens ${ }^{3}$ que contassem suas experiências com o sagrado e, também, a de perceber a repercussão entre os moradores da favela, da Missa Campal, que celebrava o Segundo Encontro Mundial das Famílias com o Papa, ocorrida no dia 05 de outubro de 1997, também no Rio de Janeiro, quando o Papa João Paulo II visitava o Brasil. Para isso, o primeiro dia de gravação do documentário é o mesmo dia que a missa está sendo celebrada e vários personagens acompanham a mesma pela televisão, nas primeiras sequências da obra. As gravações se dão entre outubro e dezembro de 1997, começando no dia da Missa Campal, e finalizado na noite de Natal, duas celebrações religiosiosas. Santo Forte é um documentário que tem na narrativa seu elemento essencial - não que as imagens não sejam importantes, pelo contrário, por ser conhecido como o filme em que seu diretor depura um minimalismo com relação às imagens e aposta no ato da comunicação, do diálogo, do

\footnotetext{
2 Ver GUIMARÃES, Patrícia. Ritual e estratégias de diferenciação simbólica no campo religioso: a Igreja Universal do Reino de Deus. Dissertação de Mestrado. Universidade do Estado do Rio de Janeiro (UERJ), 1997.

3 Esse encontro entre diretor e personagem, essencial no cinema coutiniano, só ocorre no dia da filmagem, sendo uma equipe de pesquisa, que realiza um levantamento prévio de possíveis entrevistados, coletando relatos e imagens, para o diretor selecionar os narradores de sua obra. Em Santo Forte, a equipe é composta por Patrícia Guimarães (Antropóloga), Cristiana Grumbach, Daniel Coutinho (filho do diretor) e Vera Dutra dos Santos (que também é personagem do filme).
} 
encontro e da palavra como performance e um auto narrar, as imagens tem ainda mais poder, nada é mera ilustração em Santo Forte. Ao longo de todo o documentário, temos o diálogo entre entrevistador (Coutinho) e entrevistado (morador da comunidade), com a mediação da câmera, sendo importante dizer que não há roteiro prévio e o morador e o diretor nunca se encontraram antes do momento da conversa.

Após a realização de Cabra marcado para morrer, em 1984, Coutinho passou por um período em que fez cerca de 15 trabalhos, até Santo Forte, porém, trabalhos mais pela necessidade de renda de que pelo desejo de filmar. É com Santo Forte, que o documentarista depura seu método de entrevista e dispositivos de filmes. O próprio Coutinho considera a obra uma "ressureição" de seu desejo pelo documentário, apostando na palavra do outro.

A obra foi realizada com recursos da Prefeitura da cidade do Rio de Janeiro/Secretaria Municipal de Cultura, através da Lei de Incentivo à Cultura e da RioFilme, na época vinculada à Prefeitura do Rio, sob a direção de José Carlos Avellar, e ainda, com o investimento também do Centro de Criação de Imagem popular (CECIP). A distribuição do documentário, foi dividida entre a Funarte e a Riofilme, em VHS e nos cinemas. Para além disso, o filme foi também selecionado e financiado pelo Programa Rumos - Cinema e vídeo do Itaú Cultural de 1998, na categoria produção.

O documentário gerou várias premiações a seu diretor, depois do hiato de 15 anos (desde Cabra marcado para morrer (1984)), sem lançar um longa-metragem com exibição comercial nos cinemas. Dentre eles Santo Forte ganhou de Melhor filme, roteiro, montagem e Prêmio da Crítica no Festival de Brasília (1999); O Prêmio Especial do Júri no XXVII Festival de Gramado de Cinema Latino e Brasileiro (1999); Margarida de Prata - CNBB, 1999; Prêmio para finalização do filme concedido pelo Office Catholique du Cinéma (OCIC) e Melhor filme brasileiro de 1999, pela Associação Paulista de Críticos de Arte e SESC (MATTOS, 2003). 
Nas narrativas do documentário, podemos observar as fronteiras fluidas entre as tradições religiosas presentes no Brasil. A temática do trânsito religioso é ressaltada em muitos relatos, assim como também se declarar pertencente a mais de uma religião, no caso "católico e espírita", geralmente na intenção de se referir à umbanda; ou ainda, como é o caso de Alex, alguém que se denomina católico, mas também umbandista e, que já pediu auxílio em caso de doença, para o obreiro, da igreja neopentecostal que sua mãe frequenta. Como ressalta Mesquita (2008),

Não há timidez ao assumir sua "volubilidade" em
termos de opção religiosa - pelo contrário, há um
certo gosto ao contar sobre o trânsito, as mudanças, o
entra-e-sai pouco ortodoxo por portas de igreja e
terreiros. [...] Essa liberdade para trocar de credo, de
culto, de instituição, é tratada como experiência
cotidiana e válida - não é motivo para
constrangimentos nem deve ser escondida
(MESQUITA, 2008, p. 86).

Isso não apresenta contradição alguma, pelo contrário, nos mostra, de que maneira essas religiões são apreendidas e vivenciadas por essa população, incorporando (as vezes literalmente), seus santos fortes nas lutas e mazelas cotidianas. A comunicação com deuses, espíritos, entidades e santos é narrada durante todo o filme. Vale ressaltar também, que não temos a presença de especialistas (pesquisadores) da religião ou autoridades sobre o tema, nem mesmo a presença de rituais enquanto ilustrações de uma religiosidade; o que temos são as experiências e memórias narradas, por sujeitos, historicamente localizados

Isso não quer dizer que essas religiões que aparecem em Santo forte não sejam vivenciadas na coletividade, pelo contrário, a coletividade, a comunidade, é essencial também. Porém, ao priorizar mostrar a religião a partir da narrativa e não da prática, "por opção, o cinema de Coutinho - ao 
contrário de outros filmes sobre religião - optou por se afastar do lugar coletivo e deixa-lo na "invenção" da intimidade e da intersubjetividade (QUEIROZ, 2017, p. 50).

Assim, Coutinho dialoga entre público e privado, indivíduo/grupo, porém não a partir de polarizações entre essas esferas, mas sim, mostrando como as fronteiras são fluidas e o que parece "contraditório" ou até mesmo "inferior" pelo pensamento ocidental cristão, se mostra humano e coerente em determinada vivência, tão válida quanto. A obra evidencia polifonias e, com isso, o pluralismo religioso e cultural, nem sempre pacífico, existente em nosso país. Dentre as várias possibilidades de análise, diante da proposta do evento, optamos pelo recorte de duas personagens, que abrem espaço para pensarmos as mulheres no documentário Santo Forte, sob a temática da religiosidade no cotidiano e como estratégia de sobrevivência e luta. Além disso, refletir sobre as maneiras como são representadas mulheres negras e periféricas, nesta obra cinematográfica.

\section{Mulheres de Santo Forte (1999)}

Entre os dezoito personagens da obra4, onze são mulheres, com inserções diferenciadas na obra. A partir de um recorte, escolhemos partes das narrativas de Thereza e Carla. Poderíamos porém, também citar Vera, que teve problemas com o noivo, por conta da de sua Pombagira, e também na Igreja Universal, com o então marido. O que, dentre outras coisas, a leva atualmente a não ter uma religião fixa, mas sim "fazer visitas para congregar", em diferentes igrejas evangélicas. Temos

\footnotetext{
4 Consideramos "personagens" todos os participantes que aparecem no produto final do documentário, e que estão listados no final da obra. Ressaltamos isso pois há na bibliografia especializada alguns trabalhos que consideram "personagens" apenas as pessoas as quais aparecem a legenda com o nome (como é o caso de Thereza e de Carla, nos fragmentos 1 e 2), no caso apenas 11 dos 18 participantes.
} 
também, Vanilda, que tem uma rápida inserção no documentário: aparece assistindo a missa Campal celebrada pelo Papa, e se emociona ao contar para Coutinho a promessa que havia acabado de fazer, enquanto acompanhava a cerimônia pela TV. Seu pedido era a Deus, diretamente, sem intermediários, para ter um filho. Marilena e Marlene, pelo silêncio ou inserção tímida e pequena que as mesmas possuem, sendo coadjuvantes, ou protagonistas, mas tendo sua história narrada pelo homem (Marilena), nas falas dos respectivos maridos, André e Braulino. Quinha e Lídia também poderiam ser elencadas. Ambas, fartas de sofrerem, ameaçaram matar os respectivos falecidos maridos. A primeira criou sete filhos, sem ajuda do marido, que quando vivo gastava o dinheiro da família em bebida e deixava-os passando fome. Dada a situação ela diz que:

Quinha: Eu pensei muita besteira. Foi tanta coisa que eu passei, que eu sofri eu pensava besteira.

Coutinho: O que que é pensar besteira?

Quinha: Ah, muitas vezes de eu mesma fazer justiça com as próprias mãos. Matar o pai dos meus filhos. Já pensei em me jogar. Veja, eu ia trabalhar e eu chegava no sétimo andar, eu olhava assim, e pensava. Pra me ver livre daquele sofrimento que eu tinha com ele.

Coutinho: Cê pensou em matar o teu marido e em se matar.

Quinha: E eu pensava ao mesmo tempo em me matar [afirmando com a cabeça. Depois eu disse: não, se Deus existe eu vou vencer. Se Deus me deu essa cruz ele vai me dar essa força. E eu falava, as vezes até falava sozinha na rua, poderiam até pensar que eu estava doida. Mas eu sei que não estava. Falando com Deus que eu fui atendida (SANTO FORTE, 1999).

Já Lídia, relata que quando foi morar no Rio de Janeiro com o marido, "o diabo se soltou". Ela diz que por 9 anos, levou uma vida de traição, até que um dia "me enfezei me aborreci e disse: olha você se 
dane. Saia da minha vista, porque senão eu te mato." (SANTO FORTE, 1999). Temáticas como afetividade, fome, morte, suicídio, promessas, maternidade, liberdade e relacionamentos, que demonstram a vida, e suas contingências, podem ser extraídas e relacionadas, todas, à religião, em geral como uma forma de força e proteção, quando pensada num âmbito mais privado, mas também de tentações e insuficiência das instituições (caso de Vera com a IURD) em dar conta de todas as demandas. Temos a mulher que está farta de homens, a que deseja ser mãe, a que é mãe e criou os filhos com enorme dificuldade, situação muito comum no Brasil onde o abandono paterno tem níveis altíssimos; mulheres que gostam do casamento; e mulheres que pensaram até em matar o marido, para a própria sobrevivência e resistência, demonstrando, em suas maneiras, o protagonismo que assumem (por necessidade inclusive) para com a vida e seus imbróglios.

A partir do exposto, buscamos evidenciar a multiplicidade de aberturas que o documentário possui para analisarmos as narrativas e personagens femininas, ou seja suas representações na obra. Com isso, nos aprofundaremos ainda mais nas personagens, partindo de excertos das narrativas de Thereza e Carla, especialmente quando falam sobre suas vivências nas religiões afro-brasileiras; pensando a presença das entidades do panteão umbandista, Maria Padilha e Vovó Cambinda, na vida cotidiana das moradoras.

\section{Thereza e Vovó Cambinda}

Fragmento 1 - Thereza 

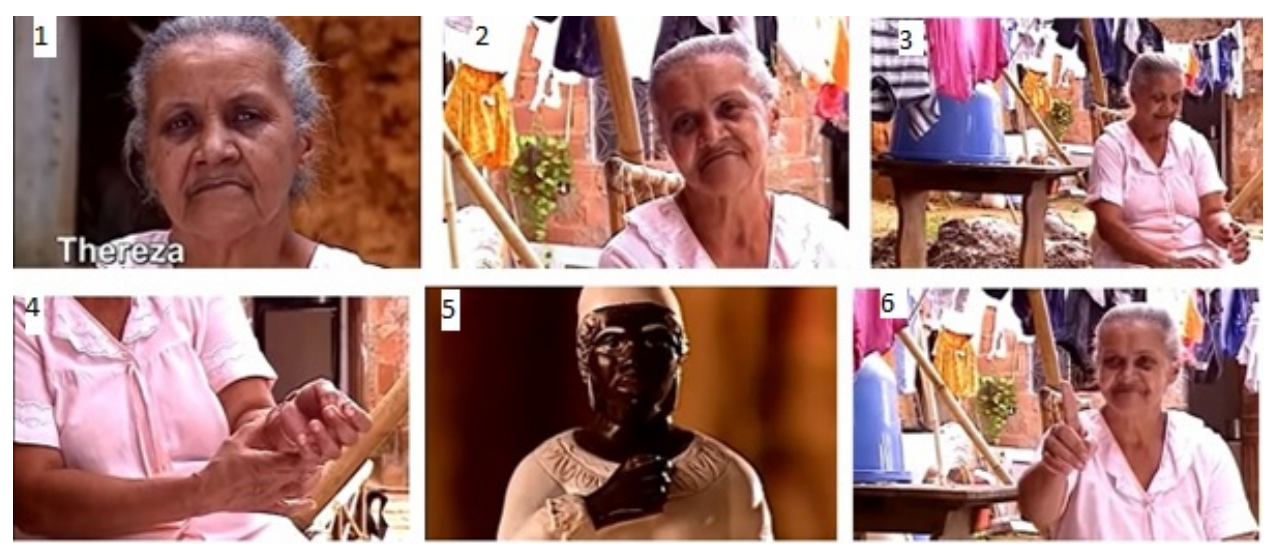

Fonte: Santo Forte, 1999.

No quadro 1 temos Dona Thereza, sentada em seu quintal, com roupas no varal penduradas ao fundo. É uma das personagens principais do documentário. Thereza começa já falando sobre seus guias e suas crenças (quadros 3 e 4):

Coutinho: o que que são essas pulseiras no seu braço?

Thereza: São dos meus guias

Coutinho: Mostra?

Thereza: Eu sou espirita. Católica espirita. Mostrar?

Coutinho: O que quer dizer cada guia dessa?

Thereza: Cada guia dessa é uma firmeza,uma segurança. E cada guia dessa pertence a um Orixá.

Coutinho: você pode mostrar cada uma de que orixá?

Thereza: posso: vovó Cambinda, Ogum, Xangô, Oxóssi, Oxum.

Coutinho: E a senhora frequentou a Umbanda a vida toda?

Thereza: Frequentei muitos anos agora eu parei né.

Coutinho: Por quê? 
Thereza: Deixei por causa de muita decepção, ingratidão. Mas eles não me abandonaram.

Coutinho: Mesmo a senhora deixando?

Thereza: mesmo eu deixando, eu cuido deles, né.

Coutinho: como é que a senhora cuida deles?

Thereza: Por exemplo, de 7 em 7 dias, segunda-feira, eu boto café pra minha velha, café margoso, pra Vovó Cambinda (SANTO FORTE, 1999).

Continuando o relato, Thereza conta como criou 6 filhos e 8 netos sozinha. Sozinha mas "com Deus" e seus guias. Quando interrogada do porquê de ter passado por essa situação ela responde: "Thereza: Porque não dei muita sorte né, meu filho. A sorte não nasceu pra todos, né. [...] O marido era uma praga. Porque era muito ruim e a ruindade destrói. Morreu de câncer, nos meus braços." (SANTO FORTE, 1999) Ao mesmo tempo que a religiosidade traz proteção e força, também faz parte do relato de Thereza, a ideia de carma, presente no espiritismo. Para ela, sua situação, de pobreza, dificuldade, e também gostos refinados (como gostar de jóias caras e de Beethoven), está relacionada à outras vidas, nas quais a personagem teria sido má, e agora estaria pagando por isso. Em contrapartida, em Vovó Cambinda, sua preta-velha (a qual ela se assemelha muito), é sinônimo de força e proteção. Ela diz:

Thereza: hoje eu não botei café pra velha, porque a velha ganhou um vinho: moscatel.

Coutinho: quem é a velha?

Thereza: É a Vovó Cambinda, não esqueça desse nome hein?! (quadro 6) Vovó Cambinda. Ela foi do tempo da escravidão.

[Corta a cena para a imagem da estátua da Vovó Cambinda (quadro 5)

Thereza: Ela é velinha. Mas é uma velha bonita. Só anda de branquinho, fuma um cachimbinho... Um dia ela disse pra mim... posso falar? 


\section{Coutinho: Pode!}

Thereza: Um dia eu falei: oh, Vovó Cambinda, eu sofro tanto. Passo por tanta coisa na vida, tanta ingratidão, tanta coisa. Tem dia que me dá vontade de desistir de viver. Ela sentada na beira da minha cama disse assim: Filha, quando você chora, eu choro junto com você, eu tô sempre com você. Te ajudando, pra você aguentar. Num é bacana isso? (SANTO FORTE, 1999)

Assim, a relação com Vovó Cambinda, é de devoção e proximidade. Thereza, mãe, negra, pobre analfabeta, em Santo Forte é também protagonista da própria vida e da própria narrativa. Possui sabedorias sobre a vida e o mundo (dos vivos e dos mortos) para conosco contribuir. Luta, a cada dia, para criar os netos, reformar o barraco e se relaciona com o sagrado para enfrentar as dificuldades do mundo. Assim como Vovó Cambinda, preta-velha que espelha sabedoria, luta e resistência no período escravocrata, que está ali ajudando Thereza a aguentar.

Carla e Maria Padilha

Fragmento 2 - Carla 

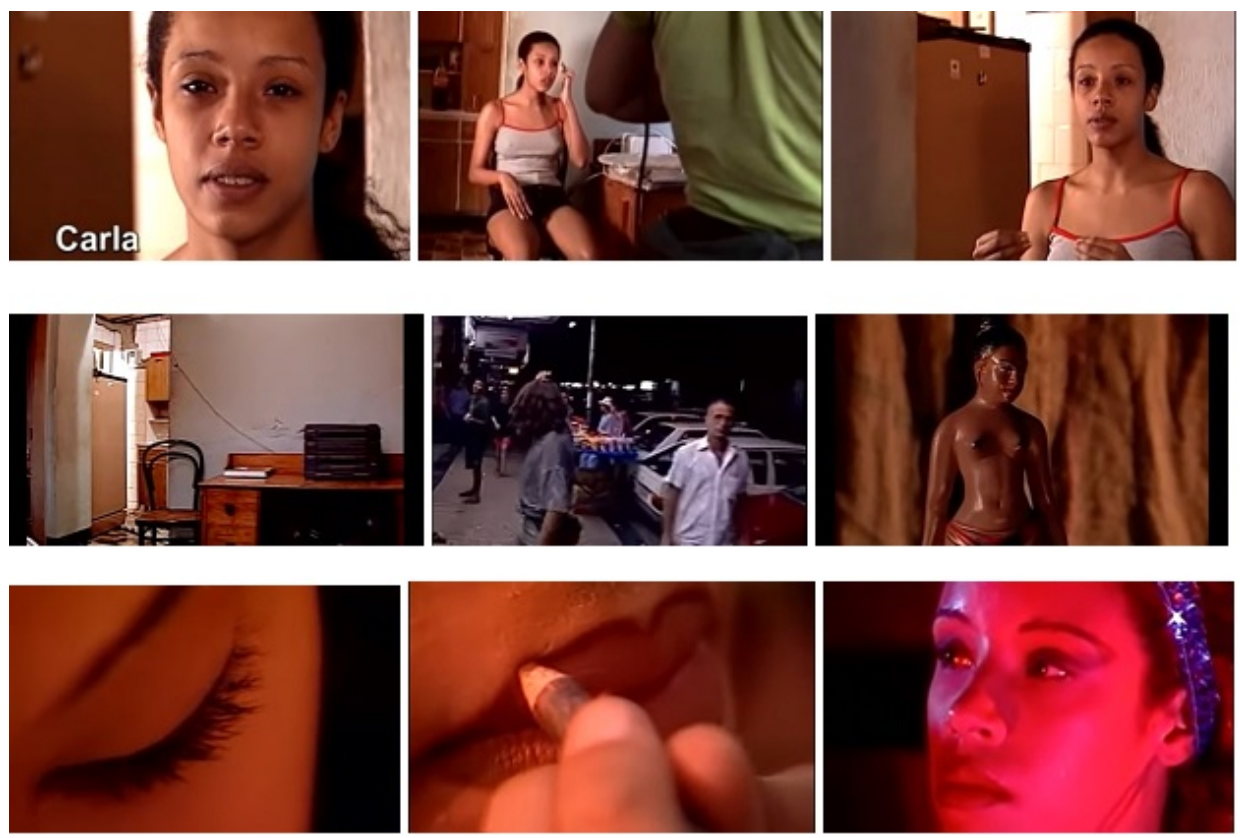

Fonte: Santo Forte, 1999.

A segunda narrativa, que nos propomos analisar é a de Carla (quadro 1). A jovem bonita e bem humorada, conta que quando criança era fanática dentro da Igreja Universal do Reino de Deus (IURD), e depois, quando foi para a Umbanda, relata uma relação ambígua com suas entidades, em especial Maria Padilha. Em seu relato, temos uma perspectiva complexa do panteão umbandista. A personagem tem uma fala marcada pela explicação de como funciona, de maneira geral o culto, falando sobre "o Povo de Luz", o Exus, as Pombagiras, e também relacionando santos católicos com os orixás. Sua narrativa abre espaço para pensarmos muitos aspectos sobre a religiosidade. Porém, o que focaremos é a relação da entrevistada com Maria Padilha, pensando o ambiente de trabalho, $\mathrm{e}$ as relações de identificação entre personagem/entidade. E também em sua conturbada inserção na umbanda, devido às experiências com um pai de santo. 
Carla: Aí algum tempo depois, eu voltei a frequentar terreiros de umbanda [dá a impressão de como se já frequentasse] só que aí eu entrei em uma que não deu muito certo...

Coutinho: você pode contar por que?

Carla: Primeiro porque o pai de santo era um charlatão. Um pai de santo ele tem uma relação. As filhas de santo dele são como se fossem filhas carnais, ele não pode tocar. E ele gostava de tocar nas filhas de santo. Gostava de ter relacionamento com filhas de santo, então daí ele começou a degringolar. A vida dele começou a degringolar e das filhas de santo também. Então isso quer dizer: assim que eu me envolvi de novo na Umbanda eu me envolvi muito mal.

Coutinho: e ele teve relacionamento com você?

Carla: teve (SANTO FORTE, 1999)

Ela conta que se envolveu mal na religião por conta disso, e então levava "surras de santo", no caso de Maria Padilha, até mesmo em sua casa (quadro 4). Quando interrogada se teria medo que Maria Padilha se vingasse dela, ela diz: "olha, eu tenho. Ainda mais no clima em que eu trabalho." (SANTO FORTE, 1999). A partir disso, as falas de Carla são intercaladas com seu ambiente de trabalho, que se relaciona com a entidade. Aparecem imagens da personagem se maquiando, como podemos ver no fragmento acima, e ela continua: "Eu trabalho fazendo show, eu trabalho tipo assim, em casa de show. E mal ou bem você tem rebarba de pessoas que já trabalharam lá... entendeu? É um lugar carregado. São lugares onde você não pode entrar sem uma proteção. [...] É pesado, porque, mal ou bem, a noite é das Pombagiras. Passou da meia-noite, a maioria das pessoas dizem que o diabo tá solto" (SANTO FORTE, 1999). Com essa fala, começa a tocar uma música e vemos imagens rápidas de Carla dançando com os seios à mostra, assim como a imagem que aparece de Maria Padilha. 
Percebemos que Carla tem uma relação complexa com sua entidade. Mesmo temendo-a, Carla diz que não pode entrar em seu trabalho sem proteção, no caso desempenhada por Padilha, uma vez que afirma que "mal ou bem a noite é das pomba-giras". Assim como Thereza, as entidades das entrevistadas estão presentes em questões cotidianas práticas e em reflexões e projeções existenciais. As duas, mulheres negras e periféricas, fazem e se utilizam do que for preciso para sobreviverem. Suas vidas estão perpassadas pelo sagrado a todo momento. $\mathrm{O}$ que nos remete às discussões de Mircea Eliade sobre o "homem religioso". Segundo Eliade, este está sempre aberto à comunicação com os deuses e conhece o sagrado quando este se manifesta. Essa manifestação é chamada pelo autor de hierofania, sendo que é a partir do estudo das mesmas que a História das Religiões e religiosidades se constitui. (ELIADE, 1992). A hierofania é então, a manifestação de algo de ordem diferente, que não pertence ao nosso mundo, que difere do profano, mas que ocorre no nosso meio. Sendo que "Para aqueles que têm uma experiência religiosa, toda natureza é suscetível de revelar-se como sacralidade cósmica. O cosmos, na sua totalidade, pode tornar-se uma hierofania" (ELIADE, 1992, p.18).

Assim, percebemos, de acordo com Mesquita, que em Santo Forte,

A força mágica e espiritual integra a vida, compõe um sistema de explicação e representação da existência, podendo ser acionada a qualquer episódio do cotidiano. Daí a ideia de uma moralidade com componentes religiosos. Isso não quer dizer moralismo ou puritanismo (a religião ditando uma conduta estrita no cotidiano).Quer dizer a presença da "religião" - ou melhor dizendo, a presença do mundo sobrenatural, com seus santos espíritos, força mágica e mistérios - se misturando ao cotidiano, povoando-o e sendo representado, nas narrativas, como repertório explicativo fundamental, força determinante das "causalidade", dos reveses, 
alegrias e reviravoltas da vida (MESQUITA, 2008, p. 85).

Temos ainda, em concordância com a análise da referida autora, que a partir das narrativas e da representação da experiência religiosa, essas mulheres afirmam um "protagonismo" no cotidiano:

protagonismo que tantas vezes lhe deve ter sido negado, por ser pobre e por ser mulher, numa cultura persistentemente machista, a despeito de tantas mudanças. Mulheres - subalternas entre os subalternos - aqui ela são protagonistas plenas; É sobretudo na fala das mulheres que a religião se transforma, em Santo Forte, em meio para autovalorização moral e afirmação de potência (MESQUITA, 2008, p. 87).

As entidades femininas da umbanda, neste caso pretas-velhas e pomba-giras, corroboram essa ideia de protagonista feminina: “As pomba-giras, personalidades emblemáticas e polêmicas, ao entrelaçarem suas histórias de vida com aqueles que delas se aproximam, têm, na maioria dos casos, o "poder" de ajudar as mulheres a repensar seu lugar e papel no mundo" (MONTORO, p. 154). As pretas-velhas, são entidades evoluídas na umbanda, e sinônimo de sabedoria, luta e resistência.

Assim, enquanto Carla é a mulher que a relação de identificação e subversão é com Padilha, que não tem seu corpo e sexualidade controlados, associada aos elementos vermelhos, mundanos, ao cigarro (aparece fumando em uma cena), à mulher livre para gargalhar e expressar sua sexualidade e corpo do jeito que lhe convir. Thereza, por sua vez, também demonstra subversão e luta, mas a partir de outra relação de identificação, com a preta-velha Vovó Cambinda, que também passou por dificuldades, e que está do lado agora da entrevistada, para ajudar-lhe a sobreviver diante do mundo. Thereza também é a mulher livre, que "faz o seu" e resiste enquanto mulher negra e periférica que construiu tudo o que tem a partir dela mesma. $\mathrm{O}$ 
que faz de Santo Forte, para finalizar, uma obra multidimensional, e sensível, que traz à tona a possibilidade de que mesmo por um momento, as entrevistadas narrem a si mesmas e tenham seu protagonismo.

\section{Referências}

ELIADE, Mircea. O sagrado e o profano. 1992.

MATTOS, Carlos A. Eduardo Coutinho - O homem que caiu na real. Festival de Cinema Luso Brasileiro de Santa Maria da Feira. Portugal, 2003.

MESQUITA, Claudia. Deus está no Particular: Representações da experiência religiosa em dois documentários brasileiros contemporâneos. Tese de doutorado. USP, 2006 .

MONTORO, T.; FERREIRA, C. Mulheres negras, religiosidades e protagonismos no cinema brasileiro. Galaxia, São Paulo, n. 27, p. 145159, jun. 2014.

MORIN, Edgar. O cinema ou o homem imaginário. Ensaio de Antropologia Sociológica. Trad. de Luciano Loprete. São Paulo, SP: É Realizações Editora, 2014.

NAPOLITANO, Marco. Fontes audiovisuais: a história depois do papel. In: PINSKY, Carla B. (Org.). Fontes Históricas. 1 ed. São Paulo: Editora Contexto, 2005, v. 1. p. 235-290

QUEIROZ, Ruben Caixeta de. Santo Forte: uma perspectiva antropológica sobre a invenção do cinema e da religião. In: ALTMANN, Eliska; BACAL, Tatiana (Org.) Santo Forte visto por. 1. ed. Rio de Janeiro: 7 Letras, 2017.

SANTO, Forte. Direção de Eduardo Coutinho. $83 \mathrm{~min}$, Riofilme/Funarte, 1999. Disponível em: https:/ / youtu.be/bf9Gijfwog. Acesso em: ago. 2020. 